American Journal of Neuroscience 3 (1): 25-31, 2012

ISSN 1948-9900

C 2012 Science Publications

\title{
YAminobutyrate B Receptors in Central Amygdaloid and Medial Amygdaloid Nuclei of Amygdala Modulate Aggression in Male Rats
}

\author{
${ }^{1}$ Mahnaz Taherianfard, ${ }^{2}$ Zahed Abdolahi, \\ ${ }^{1}$ Hamid Rajaian, ${ }^{2}$ Javad Molazadeh and ${ }^{1}$ Yosef Nemati \\ ${ }^{1}$ Depatment of Physiology, \\ Faculty of Vet Med., Shiraz University, Shiraz, Iran \\ ${ }^{2}$ Depatment of Clinical Psychology, \\ Faculty of Education and Psychology, Shiraz University, Shiraz, Iran
}

\begin{abstract}
One neurochemical system most consistently linked with aggression is the GABAergic system. The aim of the present investigation was to examine the effect of injection of baclofen $\left(\mathrm{GABA}_{\mathrm{B}}\right.$

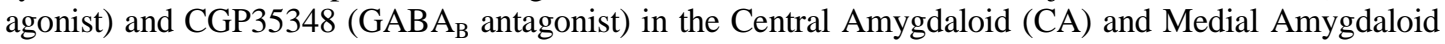
(MA) nuclei of the amygdala on offensive aggression behavior in the animal model. Sixty six adult male rats weighing 180-200g were used. Cannula was implanted into each ac and or am nuclei of amygdala using stereotaxic method. Each animal received 100 electrical shocks every session. After electrical shock, another rat was placed in the electroshock chamber and the animals were observed for various aggressive behaviors. Data were analyzed by Student's T test and one way ANOVA and Tukey's test as the post-hoc test. Significant level was considered to be $\mathrm{p}<0.05$. It was shown that injection of baclofen into the am nucleus of amygdala led to a significant increase in offensive aggression behavior, whereas baclofen injection into the ac nucleus of amygdala led to a significant decrease in offensive aggression behavior. Injection of CGP35348 into the am nucleus of amygdala caused a significant decrease in aggressive behavior, but its injection into the ac nucleus of amygdala induced a significant increase in offensive aggression behavior. Results indicated that $\mathrm{GABA}_{\mathrm{B}}$ receptors in the ac and am nuclei of amygdala are possibly involved in the modulation of offensive aggression behavior.
\end{abstract}

Key words: Aggression, amygdala, baclofen, CGP35348, Central Amygdaloid (CA), Medial Amygdaloid (MA)

\section{INTRODUCTION}

Aggressiveness is an ancestral behavior common to all animal species. Its neurophysiological mechanisms are similar in all vertebrates (Giammanco et al., 2005). The putative neural circuit of aggressive motivation identified with Functional Magnetic Resonance Imaging (FMRI) includes neural substrates contributing to emotional expression (i.e., cortical and medial amygdala, Bed nucleus of the Stria terminalis, lateral hypothalamus), emotional experience (i.e., hippocampus, forebrain cortex, anterior cingulate, retrosplenial cortex) and the anterior thalamic nuclei that bridge the motor and cognitive components of aggressive response (Ricci et al., 2009). Drugs blocking vasopressin neurotransmission or enhancing serotonin activity may suppress putative neural circuit activity of aggressive motivation, particularly the anterior thalamic nuclei (Ferris et al., 2008). Hoptman et al. (2010) reported that the less functional relationship between amygdala and the ventral prefrontal cortex is associated with higher levels of self related aggression (Hoptman et al., 2010).
The amygdala plays a crucial role in the affective evaluation of multimodal sensory input and the neurobiological mediation of aggressive behavior (Elst et al., 2000). In addition, Coccaro et al. (2007) reported that, there is a link between a dysfunctional cortico-limbic network and aggression (Coccaro et al., 2007). Stereotactic amygdalectomy can be considered a valid surgical treatment option for carefully selected patients with medically refractory aggressive behavioral disorders (Mpakopoulou et al., 2008). Emery et al. (2001) reported that amygdalectomy may increase aggression (Emery et al., 2001). Neuroanatomical studies show that stimulation of the medial amygdala and the ventromedial nucleus increases aggression in rodents while lesions in these nuclei cause an opposite effect (Spiteri et al., 2010). In the lactating rat, oxytocin receptors (OXT-R) are up-regulated in certain brain areas including the central amygdala (CeA), a part of the limbic system relevant to the regulation of aggression (Bosch and Neumann, 2010).

There are several evidences with respect to the involvement of GABA in aggression. For example, after 
Am. J. Neuroscience 3 (1): 25-31, 2012

measurement of GABA concentrations in the brain of aggressive mice, Sustkova-Fiserova et al. (2009) suggest that the GABAergic system represents an important molecular and neuronal substrate for the selective attenuation of anxiety and aggression (Sustkova-Fiserova et al., 2009). In addition, Bjork et al. (2001) reported that low GABA levels may correlate with some aspects of aggressiveness which may be genetically regulated (Bjork et al., 2001). The possible role of GABA in human aggression has also been evaluated by administering baclofen to subjects, with or without a history of conduct disorder, followed by comparing the effects on laboratory measures of aggression (Cherek et al., 2004).

The primary aim of the present study was to investigate the effects of baclofen $\left(\mathrm{GABA}_{\mathrm{B}}\right.$ agonist) and CGP35348 (GABA ${ }_{B}$ antagonist) injection into the central amygdaloidal (ac) and medial amygdaloidal (am) nuclei of amygdala on offensive aggression behavior in male rats.

\section{MATERIALS AND METHODS}

Animals: Sixty six male Sprague-Dawley rats weighing 180-200g were used. Food and water were available ad libitum, under a $12 \mathrm{~h} \mathrm{light/dark} \mathrm{(lights} \mathrm{on} \mathrm{at} 6$ a.m. and off at 6 p.m.) and controlled temperature $\left(21-24^{\circ} \mathrm{C}\right)$.

The animals were tested for aggression in three groups: 1- control group; animals without receiving any drug $(\mathrm{n}=6) ; 2$-sham group; animals were injected $2 \mu \mathrm{L}$ of Artificial Cerebrospinal Fluid (ACSF) in the ac or am nuclei of amygdala $(\mathrm{n}=12)$; 3 -experimental group; animals were injected $2 \mu 1$ baclofen (4.27 and $8.54 \mathrm{ng}$ $\left.\mathrm{rat}^{-1}, \mathrm{n}=24\right)$ and CGP35348 (1.5 and $\left.3 \mathrm{ng} \mathrm{rat}^{-1}, \mathrm{n}=24\right)$ in the ac or am nuclei of amygdala, respectively.

Behavioral testing: Rats were placed in a plastic box $(48 \times 32 \times 40 \mathrm{~cm})$ with an electrifiable grid floor. Offensive aggression was induced by $0.2 \mathrm{~mA}$ for one sec electrical current stimulation applied every $3 \mathrm{sec}$ for 5 min, i.e., each animal received 100 electrical shocks every session (Baggio and Ferrari, 1980). After electrical shock, another rat was placed in the electroshock chamber and the animals were monitored for the signs of various offensive aggression behaviors and these were appropriately recorded by camera for 20 $\min$. The behaviors observed in the experiments were: (a) approaching movements toward other rats; (b) threat- head movement toward the other rat; (c) offensive upright- aggressive rat stands on hind legs, head oriented toward the other rat; (d) offensive sideway-aggressive rat approaches the other rat broadside; (e) thrust movement of the whole forefront of the aggressive rat's body toward the other rat; (f) aggressive groom- nibbling on the grooming fur of the other rat; (g) rapid-attack-movement towards the other rat; (h) bite-biting the other rat. Frequency score were determined by counting the number of instances of each behavior during the $20 \mathrm{~min}$ of camera recording. Each rat received only one time shock.

Surgical procedure: Animals were anesthetized with an IP injection of a combination of ketamine $(50 \mathrm{mg}$ $\left.\mathrm{kg}^{-1}\right)$ and xylazine $\left(20 \mathrm{mg} \mathrm{kg}^{-1}\right)$. A guide cannula was implanted unilaterally in each rat with a 23 -gauge needle aimed at the am or ac nuclei of amygdala. Two screws were placed in the skull and each cannula was anchored into place using dental cement around the guide cannula and screws. A stainless steel probe extending just beyond the tip of the cannula was inserted during surgery and was left in place until the injection time. Each animal was allowed to recover for at least 7 days after surgery (Soigneir et al., 2000). For drug infusion a 30 gauge dentistry needle and $1 \mu \mathrm{L}$ Hamilton syringe were connected to each other by optimum size of polyethylene tube and the free side of dentistry needle was inserted in guide cannula and injection was performed during $10 \mathrm{~min}$.

Histology: The rats were exposed to a lethal concentration of ether after the accomplishment of testing. The microinjection site was marked by injecting cresyl violet $(0.2 \mu \mathrm{L})$ into the ac and am nuclei of amygdala. Subsequently, the brains were removed and placed in 10\% formaldehyde solution. Coronal sections were prepared to check if surgery was performed correctly.

Statistical analysis: Data were analyzed separately for each group with Student's $\mathrm{T}$ test for comparison of behavior score in ac and am nuclei And One way Analysis of Variance (ANOVA) for comparison of groups; Posthoc analysis was performed with Tukey's test. Data are presented as Mean $\pm \mathrm{SEM}$. The level of significance was considered to be $\mathrm{p}<0.05$.

\section{RESULTS}

Effect of baclofen injection in ac and am nuclei of amygdala on aggressive behavior: Figure $1 \mathrm{~A}$ shows that after the injection of baclofen $\left(8.54 \mathrm{ng} \mathrm{rat}^{-1}\right)$ in the ac nucleus of amygdala, some offensive aggression behavior such as threat- head movement towards the other rat $\mathrm{F}(3,13)=11.1, \mathrm{p}=0.002(10.5 \pm 2.3 ; 10.3 \pm 2.3$; $9.6 \pm 2.2 ; 2.0 \pm 0.4$ ) (The numbers are mean $\pm \mathrm{SE}$ for control, sham, baclofen $4.27 \mathrm{ng} \mathrm{rat}^{-1}$ and baclofen 8.54

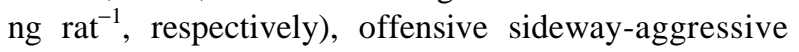
rat approaches the other rat broadside $\mathrm{F}(3,13)=10.2$, $\mathrm{p}=0.008(10.8 \pm 4.3 ; 9.5 \pm 4.4 ; 8.2 \pm 1.8 ; 3.8 \pm 1.7)$ and aggressive groom-nibbling on the grooming fur of the other rat $\mathrm{F}(3,13)=9.5, \mathrm{p}=0.009(1.2 \pm 0.1$; $1.5 \pm 0.8 ; \quad 2.5 \pm 0.2 ; \quad 0.5 \pm 0.01)$ were significantly decreased compared to the control and sham groups. 
Am. J. Neuroscience 3 (1): 25-31, 2012

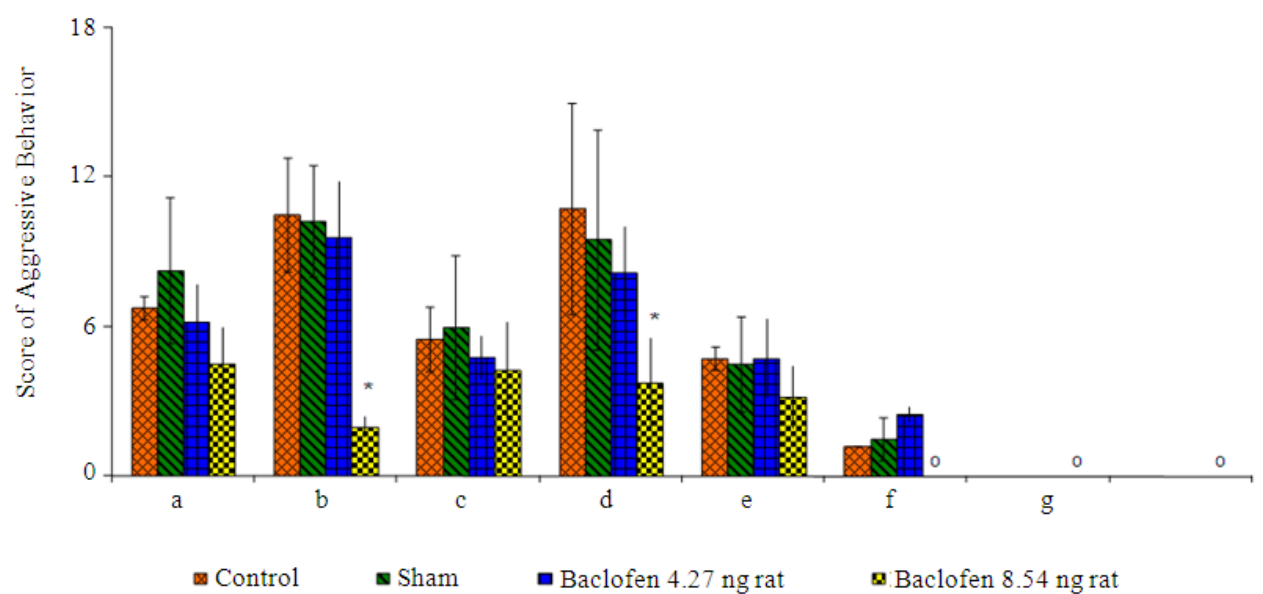

(a)

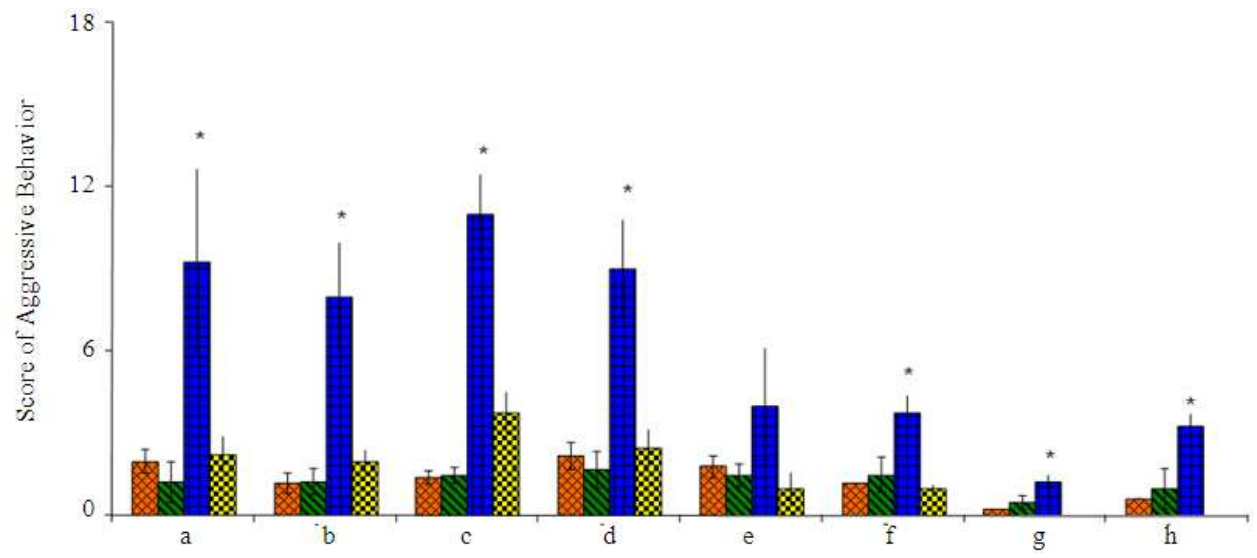

(b)

Fig.1:Effect of baclofen injection in ac nucleus of amygdala (A) and baclofen injection in am nucleus of amygdala (B) on aggressive behavior. Score of aggressive behavior is according to the number of each behavior during $20 \mathrm{~min}$ of camera recording. The behaviors observed in these experiments were: (a) Approaching movements toward other rats (b) Threat- head movement toward the other rat (c) Offensive upright- aggressive rat stands on hind legs, head oriented towards the other rat (d) Offensive sideway- aggressive rat approaches the other rat broadside (e) Thrust movement of the whole forefront of the aggressive rat's body toward the other rat (f) Aggressive groom- nibbling on grooming fur of the other rat (g) Rapid- attack- movement towards the other rat (h) Bitebiting the other rat * Significantly $(\mathrm{p}<0.05)$ different compared to those in control and sham groups $(n=6)$

There were no significant changes in animals receiving both doses with respect to other offensive aggression behaviors that were considered in this study.

Figure 1B also shows that after injection of baclofen $4.27 \mathrm{ng} \mathrm{rat}^{-1}$ in the am nucleus of amygdala, some offensive aggression behavior such as approaching movements toward other rats $\mathrm{F}(3,12)=5.91, \mathrm{p}=0.016$ $(2.0 \pm 0.4 ; 1.3 \pm 0.8 ; 9.3 \pm 3.4 ; 2.3 \pm 0.6$ ) (The numbers are mean \pm SE for control, sham, baclofen $4.27 \mathrm{ng} \mathrm{rat}^{-1}$ and baclofen $8.54 \mathrm{ng} \mathrm{rat}^{-1}$, respectively).

Threat-head movement towards the other rat $\mathrm{F}(3,12)$ $=12.9, \mathrm{p}=0.001(1.2 \pm 0.3 ; 1.3 \pm 0.4 ; 8.0 \pm 1.9 ; 2.0 \pm 0.4)$, offensive upright-aggressive rat stands on hind legs
$\mathrm{F}(3,12)=16.52, \mathrm{p}=0.000(1.4 \pm 0.2 ; 1.5 \pm 0.2 ; 11.0 \pm 1.4$; $3.8 \pm 0.8$ ), offensive sideway-aggressive rat approaches the other rat broadside $\mathrm{F}(3,12)=32.9, \mathrm{p}=0.000(2.2 \pm 0.4$; $1.7 \pm 0.6 ; 9.0 \pm 1.7 ; 2.5 \pm 0.6$ ), aggressive groom-nibbling on the grooming fur of the other rat $\mathrm{F}(3,12)=6.8, \mathrm{p}=0.011$ $(1.2 \pm 0.1 ; \quad 0.5 \pm 0.1 ; \quad 3.8 \pm 0.6 ; \quad 1.0 \pm 0.1)^{1}$, rapid- attackmovement towards the other rat $\mathrm{F}(3,12)=6.5, \mathrm{p}=0.012$ $(0.3 \pm 0.01 ; 0.5 \pm 0.03 ; 1.3 \pm 0.3 ; 0.7 \pm 0.1)^{1}$ and bite- biting the other rat $\mathrm{F}(3,12)=34.32, \mathrm{p}=0.000(0.6 \pm 0.02 ; 1 \pm 0.2$; $3.3 \pm 0.4 ; 0.8 \pm 0.1)^{1}$ were significantly increased compared to the control and sham groups. There were no significant changes in the animals receiving both doses with respect to other offensive aggression behaviors that were considered in this study. 
Am. J. Neuroscience 3 (1): 25-31, 2012
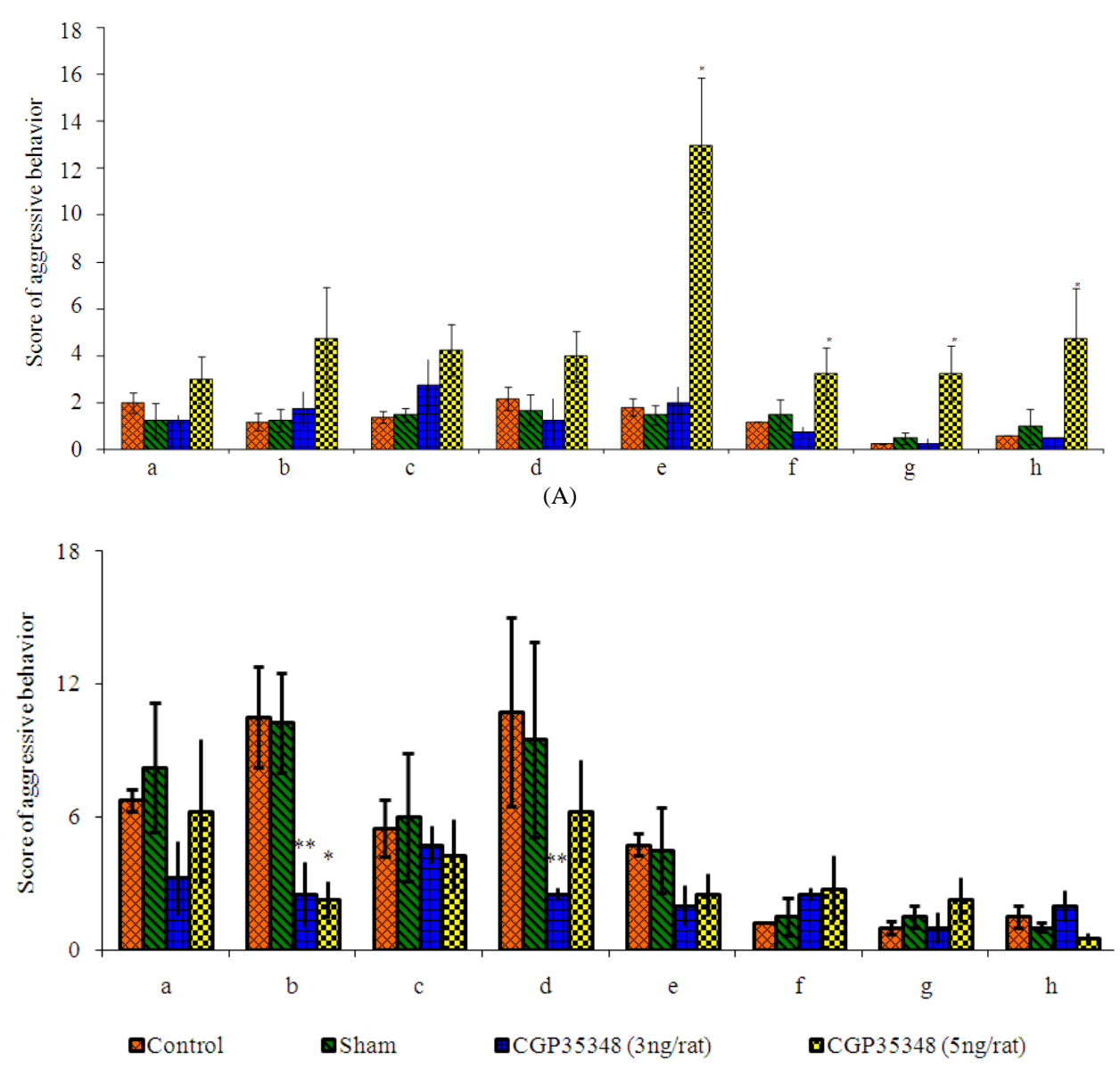

(B)

Fig. 2: Effect of CGP35348 injection in ac nucleus of amygdala (A) and CGP35348 injection in am nucleus of amygdala (B) on aggressive behavior. Score of aggressive behavior is according to the number of each behavior during $20 \mathrm{~min}$ of camera recording. The behaviors observed in these experiments were: (a) Approaching movements toward other rats (b) Threat- head movement towards the other rat (c) Offensive upright- aggressive rat stands on hind legs, head oriented towards the other rat (d) Offensive sidewayaggressive rat approaches the other rat broadside (e) Thrust movement of the whole forefront of the aggressive rat's body toward the other rat (f) Aggressive groom- nibbling on grooming fur of the other rat (g) Rapid- attack- movement towards the other rat (h) Bite- biting the other rat * Significantly $(\mathrm{p}<0.05)$ different compared to those in control and sham groups $(n=6)$

Effect of CGP35348 injection in ac and am nuclei of amygdala on aggressive behavior: Figure $2 \mathrm{~A}$ shows that after injection of CGP35348, $5 \mathrm{ng} \mathrm{rat}^{-1}$ in the ac nucleus of amygdala, several offensive aggression behaviors such as thrust movement of the whole forefront of the aggressive rat's body towards the other $\operatorname{rat} \mathrm{F}(1,12)=12.32, \mathrm{p}=0.001(1.8 \pm 0.3 ; 1.5 \pm 0.4 ; 2.0 \pm 0.7$; $13.0 \pm 2.8$ ), aggressive groom- nibbling on the grooming fur of the other rat $\mathrm{F}(1,12)=6.8, \mathrm{p}=0.011(1.2 \pm 0.2$; $1.5 \pm 0.6 ; 0.8 \pm 0.3 ; 3.3 \pm 1.1$ ) (The numbers are mean $\pm \mathrm{SE}$ for control, sham, CGP35348 3ng rat ${ }^{-1}$ and CGP35348 5 ng rat $^{-1}$, respectively), rapid- attack- movement towards the other rat $\mathrm{F}(1,12)=6.5, \mathrm{p}=0.012(0.3 \pm 0.01 ; 0.5 \pm 0.3$; $0.3 \pm 0.02,3.3 \pm 1.1)^{2}$ and bite- biting the other rat $\mathrm{F}(1,12)$ $=34.3, \mathrm{p}=0.000(0.6 \pm 0.02 ; 1.0 \pm 0.5 ; 0.5 \pm 0.1 ; 4.8 \pm 2.1)^{2}$ were significantly increased compared to the control and sham groups. There were no significant changes in the animals receiving both doses with respect to the other offensive aggression behaviors.

Figure 2B also shows that after injection of CGP35348 (3 and $5 \mathrm{ng} \mathrm{rat}^{-1}$ ) in the am nucleus of amygdala, threat- head movement towards the other rat behavior $\mathrm{F}(1,12)=8.37, \mathrm{p}=0.005(10.5 \pm 2.2$; $10.3 \pm 2.2 ; 2.5 \pm 1.4 ; 2.3 \pm 0.8)^{2}$ was significantly $(\mathrm{p}<0.05)$ 
decreased. There were no significant changes in animals receiving both doses with respect to the other offensive aggression behaviors; but CGP35348 (3 ng rat $\left.^{-1}\right)$ significantly $(\mathrm{p}<0.05)$ decreased offensive sideway- aggressive rat approaches the other rat broadside behavior $\mathrm{F}(1,12)=7.42, \mathrm{p}=0.01(10.8 \pm 4.3$; $9.5 \pm 4.4 ; 2.5 \pm 0.2 ; 6.3 \pm 2.3$ ) compared to the control and sham groups. There were no significant changes in animals receiving both doses.

\section{DISCUSSION}

Psychopharmacologic studies of aggressive behavior in animals under controlled laboratory conditions have been instrumental in developing and evaluating specific and effective novel drug therapies reducing aggressive behavior (Miczek et al., 2004). Bjork et al. (2001) suggest that low GABA levels may correlate with some aspects of aggressiveness and may be genetically regulated.

According to, Rudissaar et al. (2000) it can be proposed that both $\mathrm{GABA}_{\mathrm{A}}$ and $\mathrm{GABA}_{\mathrm{B}}$ receptor subtypes are involved in the neurobiology of apomorphine-induced aggressive behavior, as this phenomenon is evidently subject to the general inhibitory effect of GABAergic neurotransmission (Rudissaar et al., 2000). So, both $\mathrm{GABA}_{\mathrm{A}}$ and $\mathrm{GABA}_{\mathrm{B}}$ receptor subtypes are involved in aggressive behavior, but with different mechanisms. Modulation of aggression mediated by the $\mathrm{GABA}_{\mathrm{A}}$ receptor is possibly due to neurosteroides activation of these receptors. $\mathrm{GABA}_{\mathrm{B}}$ receptor activation in the dorsal raphe nucleus, however, led to an increase in the extracellular serotonin level in the medial prefrontal cortex. This means that the amplification effect of $\mathrm{GABA}_{B}$ agonist baclofen on aggression is dependent on the activation of serotonin neurons. It should be mentioned that both $\mathrm{GABA}_{\mathrm{A}}$ and $\mathrm{GABA}_{\mathrm{B}}$ receptors are expressed in the dorsal raphe nucleus of mice and play a role in the aggression behavior (Takahashi et al., 2010a; 2010b). On the other hand, according to the report of Cherek et al. (2002), amygdala is one of the brain structures involved in aggression, possibly due to several neurotransmitters such as GABA and serotonin (Cherek et al., 2002).

The effect of the injection of muscimol and picrotoxin in the ac and am nuclei of amygdala was previously investigated. It was found that the $\mathrm{GABA}_{\mathrm{A}}$ receptor in amygdala has an important role in aggression behavior (Taherianfard et al., 2010).

Role of baclofen in offensive aggression: In the present study, baclofen injected into the ac nucleus of amygdala decreased offensive aggression, but when it was injected into the am nucleus of amygdala offensive aggression increased. On the other hand, behavioral patterns were different after the injection of baclofen into these two nuclei. It seems that baclofen might act on different subtypes of $\mathrm{GABA}_{\mathrm{B}}$ receptors in the different nuclei.

Cherek et al. (2002) reported that aggressive responses in subjects with a history of childhood Conduct Disorder (CD+) will be suppressed by baclofen, while the opposite effect is induced in the control subjects. This suggests the possibility of a unique role for GABA receptors in the regulation of aggression in the CD+ population (Cherek et al., 2002). Gabapentin produces similar bitonic effects upon aggressive and escape responses in subjects with and without a history of childhood conduct disorder. This is in contrast to the previously reported differential effects of baclofen on aggressive responses between $\mathrm{CD}$ and non-CD control subjects (Cherek et al., 2004).

Accidental exposure to trimethyltin (TMT) has been reported to induce aggressiveness in humans. In addition, TMT has been shown to induce changes in the mRNA levels of major components in the GABAergic system. For example, Glutamate Decarboxylase (GAD)-65 and GAD-67, the rate-limiting enzymes involved in GABA synthesis, the $\mathrm{GABA}_{\mathrm{B}}$ receptor in the hippocampus, medial and lateral amygdaloid nuclei and piriform cortex are affected at different intervals after oral administration of TMT in rats (Nishimura et al., 2001). Moreover, Mombereau et al. (2004) demonstrated that depletion of the $\mathrm{GABA}_{\mathrm{B}}$ receptor subunit may result in an increased resistance to stressinduced behavioral despair (Mombereau et al., 2004).

Effect of CGP35348 on offensive aggression: In the present study, CGP35348 injection into the ac nucleus of amygdala increased offensive aggression, but its injection in the am nucleus of amygdala illustrated the opposite effect. It seems that CGP35348 in these two nuclei may act on different subtypes of $\mathrm{GABA}_{B}$ receptors (it means that one of them act presynaptically and the other act postsynaptically), as behavioral patterns were different after the injection of CGP35348 into the nuclei. No report has been found with respect to the effect of CGP35348 or other $\mathrm{GABA}_{\mathrm{B}}$ receptor antagonists on aggression behavior. Mombereau et al. (2004) reported that CGP56433, as a $\mathrm{GABA}_{\mathrm{B}}$ receptor antagonist, induces an antidepressant effect in the animal model of depression (Mombereau et al., 2004). Tsai and Stan (2006) reported that ICV injection of $\mathrm{GABA}_{\mathrm{B}}$ receptor antagonist (CGP35348) abolished the difference in interpulse intervals between seizure and control animals (Tsai and Stan, 2006).

It is generally concluded that: $\mathrm{GABA}_{\mathrm{B}}$ receptors are metabotropic receptors that can act presynaptically or postsynaptically. According to the data in amygdala, $\mathrm{GABA}_{\mathrm{B}}$ receptors act as autoreceptors that can 
modulate the release of GABA, glutamate and serotonin (Silberman et al., 2009). The responses induced by CGP35348 and baclofen in the present study seem to arise from a single mechanism; i.e. similar subtypes of receptors are possibly involved.

Fujimura et al. (2005) reported that the $\mathrm{GABA}_{\mathrm{A}}$ receptor expression in the ac nucleus of amygdala is stronger than that of the am nucleus (Fujimura et al., 2005). No reference was found in the literature illustrating the rate of $\mathrm{GABA}_{\mathrm{B}}$ receptor expression in amygdala; however, it seems that the rate of $G A B A_{B}$ receptor expression, as well as $\mathrm{GABA}_{\mathrm{A}}$ receptor expression in these two nuclei is different. Therefore, although similar receptors are involved in the ac and am nuclei, they may respond differently with respect to the offensive aggression behaviors.

\section{CONCLUSION}

It is generally concluded that:

- $\mathrm{GABA}_{\mathrm{B}}$ receptors are metabotropic receptors that can act presynaptically or postsynaptically. According to the data in amygdala, $\mathrm{GABA}_{\mathrm{B}}$ receptors act as autoreceptors that can modulate the release of GABA, glutamate and serotonin (Silberman et al., 2009). The responses induced by CGP35348 and baclofen in the present study seem to arise from a single mechanism; i.e. similar subtypes of receptors are possibly involved

- Fujimura et al. (2005) reported that the $\mathrm{GABA}_{\mathrm{A}}$ receptor expression in the ac nucleus of amygdala is stronger than that of the am nucleus (Fujimura et al. 2005). No reference was found in the literature illustrating the rate of $\mathrm{GABA}_{\mathrm{B}}$ receptor expression in amygdala; however, it seems that the rate of $\mathrm{GABA}_{\mathrm{B}}$ receptor expression, as well as $\mathrm{GABA}_{\mathrm{A}}$ receptor expression in these two nuclei is different. Therefore, although similar receptors are involved in the ac and am nuclei, they may respond differently with respect to the offensive aggression behaviors

\section{REFERENCES}

Baggio, G. and F. Ferrari, 1980. Role of brain dopaminergic mechanisms in rodent aggressive behavior: Influence of $( \pm) N$ - $n$-propylnorapomorphine on three experimental models. Psychopharmacology, 70: 63-68. DOI: 10.1007/BF00432371

Bjork, J.M., F.G. Moeller, G.L. Kramer, M. Kram and A. Suris et al., 2001. Plasma GABA levels correlate with aggressiveness in relatives of patients with unipolar depressive disorder. Psychiatry Res., 101: 131-136. DOI: 10.1016/S0165-1781(01)00220-7
Bosch, O.J. and I.D. Neumann, 2010. Vasopressin released within the central amygdala promotes maternal aggression. Eur. J. Neurosci., 31: 883891. DOI: 10.1111/j.1460-9568.2010.07115.x

Cherek, D.R., O.V. Tcheremissine, S.D. Lane and C.J. Pietras, 2004. Acute effects of gabapentin on laboratory measures of aggressive and escape responses of adult parolees with and without a history of conduct disorder. Psychopharmacology, 171: 405-412. DOI: 10.1007/s00213-003-1590-z

Cherek, D.R., S.D. Lane, C.J. Pietras, J. Sharon and J.L. Steinberg, 2002. Acute effects of baclofen, a $\gamma-$ aminobutyric acid-B agonist, on laboratory measures of aggressive and escape responses of adult male parolees with and without a history of conduct disorder. Psychopharmacology, 164: 160167. DOI: $10.1007 / \mathrm{s} 00213-002-1167-2$

Coccaro, E.F., M.S. Mccloskey, D.A. Fitzgerald and K.L. Phan, 2007. Amygdala and orbitofrontal reactivity to social threat in individuals with impulsive aggression. Biol. Psychiatry, 62: 168178. DOI: 10.1016/j.biopsych.2006.08.024

Elst, L.T.V., F.G. Woermann, L. Lemieux, P.J. Thompson and M.R. Trimble, 2000. Affective aggression in patients with temporal lobe epilepsy: A quantitative MRI study of the amygdala. Brain, 123: 234-243 DOI: 10.1093/brain/123.2.234

Emery, N.J., J.P. Capitanio, W.A. Mason, C.J. Machado and S.P. Mendoza et al., 2001. The effects of bilateral lesions of the amygdala on dyadic social interactions in rhesus monkeys (Macaca mulatta). Behav Neurosci., 115: 515-544 DOI: 10.1037//0735-7044.115.3.515

Ferris, C.F., T. Stolberg, P. Kulkarni, M. Murugavel and R. Blanchard et al., 2008. Imaging the neural circuitry and chemical control of aggressive motivation. BMC Neurosci., 9: 111-111. DOI: 10.1186/1471-2202-9-111

Fujimura, J., M. Nagano and H. Suzuki, 2005. Differential expression of $\mathrm{GABA}_{\mathrm{A}}$ receptor subunits in the distinct nuclei of the rat amygdala. Brain Res. Mol. Brain Res., 138: 17-23. DOI: 10.1016/j.molbrainres.2005.03.013

Giammanco, M., G. Tabacchi, S. Giammanco, D. Di Majo and M.L. Guardia, 2005. Testosterone and aggressiveness. Med. Sci. Monit, 11: RA136RA145. PMID: 15795710

Hoptman, M.J., D. D'Angelo, D. Catalano, C.J. Mauro and Z.E. Shehzad et al., 2010 Amygdalofrontal functional disconnectivity and aggression in schizophrenia. Schizophr Bull 36: 1020-1028. DOI: $10.1093 /$ schbul/sbp012 
Miczek, K.A., S. Faccidomo, R.M.D. Almeida, M. Bannai and E.W. Fish et al., 2004. Escalated aggressive behavior: new pharmacotherapeutic approaches and opportunities. Ann. N. Y. Acad. Sci., 1036: 336-355. DOI: 10.1196/annals.1330.021

Mombereau, C., K. Kaupmann, W. Froestl, G. Sansig and H. Van Der Putten et al., 2004. Genetic and pharmacological evidence of a role for $\mathrm{GABA}_{\mathrm{B}}$ receptors in the modulation of anxiety-and antidepressant-like behavior. Neuropsychopharmacology, 29: 1050-1062. DOI: 10.1038/sj.npp.1300413

Mpakopoulou, M., H. Gatos, A. Brotis, K.N. Paterakis and K.N. Fountas, 2008. Stereotactic amygdalotomy in the management of severe aggressive behavioral disorders. Neurosurg Focus, 25: E6-E6. DOI: 10.1038/sj.npp.1300413

Nishimura, T., C. Schwarzer, S. Furtinger, H. Imai and N. Kato et al., 2001. Changes in the GABA-ergic system induced by trimethyltin application in the rat. Brain Res Mol Brain Res., 97: 1-6. DOI: 10.1016/S0169-328X(01)00278-9

Ricci, L.A., J.J. Schwartzer and R.H. Melloni Jr., 2009. Alterations in the anterior hypothalamic dopamine system in aggressive adolescent AAS-treated hamsters. Horm. Behav., 55: 348-355. DOI: 10.1016/j.yhbeh.2008.10.011

Rudissaar, R., K. Pruus, T. Skrebuhhova-Malmros, L. Allikmets and V. Matto, 2000. Involvement of GABAergic neurotransmission in the neurobiology of the apomorphine-induced aggressive behavior paradigm, a model of psychotic behavior in rats. Methods Find Exp. Clin. Pharmacol., 22: 637-640. DOI:10.1358/mf.2000.22.8.802276

Silberman, Y., O.J. Ariwodola and J.L. Weiner, 2009. Differential effects of $\mathrm{GABA}_{\mathrm{B}}$ autoreceptor activation on ethanol potentiation of local and lateral paracapsular GABAergic synapses in the rat basolateral amygdala. Neuropharmacology, 56: 886-895. DOI: 10.1016/j.neuropharm.2009.01.013
Soigneir, R.D., A.L. Vaccarino, A.M. Bernnan, A.J. Kastin and J.E. Zadina, 2000. Analgesic effects of endomorphin-1 and endomorphin-2 in the formalin test in mice. Life Sci., 67: 907-912. DOI: 10.1016/S0024-3205(00)00689-5

Spiteri, T., S. Musatov, S. Ogawa, A. Ribeiro and D.W. Pfaff et al., 2010. The role of the estrogen receptor $\alpha$ in the medial amygdala and ventromedial nucleus of the hypothalamus in social recognition, anxiety and aggression. Behav. Brain Res., 210: 211-220. DOI: 10.1016/j.bbr.2010.02.033

Sustkova-Fiserova, M., J. Vavrova and M. Krsiak, 2009. Brain levels of GABA, glutamate and aspartate in sociable, aggressive and timid mice: An in vivo microdialysis study. Neuro. Endocrinol. Lett., 30: 79-84. PMID: 19300401

Taherianfard, M., Z. Abdollahi, H. Rajaian and J. Mollazadeh, 2010. Effect of muscimol and picrotoxin injection in am and ac nucleus of amygdala on aggressive behavior. Physiol. Pharmacol., 14: 155-164.

Takahashi, A., A. Shimamoto, C.O. Boyson, J.F. Debold and K.A. Miczek, 2010a. GABA B $_{\text {receptor }}$ modulation of serotonin neurons in the dorsal raphé nucleus and escalation of aggression in mice. $\mathrm{J}$. Neurosci., $\quad 30$ : 11771-11780. DOI: 10.1523/JNEUROSCI.1814-10.2010

Takahashi, A., C. Kwa, J.F. Debold and K.A. Miczek, 2010b. $\mathrm{GABA}_{\mathrm{A}}$ receptors in the dorsal raphé nucleus of mice: escalation of aggression after alcohol consumption. Psychopharmacology, 211: 467-477. DOI: 10.1007/s00213-010-1920-x

Tsai, M.L. and L.L. Stan, 2006. Decrease of hippocampal GABAB receptor-mediated inhibition after hyperthermia-induced seizures in immature rats. Epilepsia, 47: 277-287. DOI: 10.1111/j.15281167.2006.00419.x 